Psychology of Language and Communication 2016, Vol. 20, No. 3

DE GEUYTER

国

DOI: $10.1515 /$ plc-2016-0018

ANNA M. KOŁODZIEJCZYK ${ }^{1}$, SANDRA L. BOSACKI ${ }^{2}$

${ }^{1}$ Jagiellonian University, Kraków

${ }^{2}$ Brock University, St. Catharines

\title{
YOUNG-SCHOOL-AGED CHILDREN'S USE OF DIRECT AND INDIRECT PERSUASION: ROLE OF INTENTIONALITY UNDERSTANDING
}

\begin{abstract}
Recent research suggests that social cognitive abilities, particularly the theory of mind (ToM), play a role in the development of persuasion in early and middle childhood. This study investigated the relations between children's intentionality understanding and early persuasive skills, especially the ability to use direct and indirect persuasive strategies in symmetric and asymmetric relational context. Ninety-five 5- to 7-year-olds participated in a narrative task that described persuasive situations with parents and peers and answered questions in intentionality understanding stories. Results showed that participants used indirect strategies less often than direct proposals. To persuade their parents, participants used more direct than indirect persuasive strategies, while this difference was not significant for peer persuasion. Correlation analysis revealed that independent of age and expressive language ability, intentionality understanding significantly predicted participants' number of persuasive proposals and the use of direct and indirect bilateral persuasive strategies. Implications for theory and practice are discussed.
\end{abstract}

Key words: persuasion, advanced ToM, social skills, intentionality understanding

Persuasion is a communicative activity that refers to the ability to convince someone to agree with a belief or course of action (Griffin, 2011; Searle, 1983). The influence on the autonomous judgments and actions of others is possible through both direct as well as indirect methods (Tokarz, 2006). Persuasion is considered to be a social process that illustrates the ability to use social understanding in everyday contexts. Research shows that the cognitive determinants of children's persuasion skills, such as perspective-taking (Yeates, Schultz, \& Selman, 1991),

Address for correspondence: Anna M. Kołodziejczyk, Institute of Psychology, Jagiellonian University, ul. Ingardena 6, 30-060 Kraków, Poland. E-mail: anna.kolodziejczyk@uj.edu.pl 
and theory of mind (ToM) understanding (Slaughter, Peterson, \& Moore, 2013) may influence the child's persuasive communicative ability.

Research with preschoolers has found that ToM understanding predicted persuasive skills in child-adult interactions (Bartsch, London, \& Campbell, 2007) and in social situations with peers (Slaughter et al., 2013). Given that the persuasion process is often viewed as an aspect of intentional communication (Griffin, 2011; Searle, 1983), the current study is guided by Mull and Evans' (2010) claim that intentionality understanding in middle childhood may influence children's social abilities and, as we think, the ability to engage in persuasion.

\section{Direct and Indirect Persuasion}

Although persuasion is a human communication designed to influence the autonomous judgments and actions of others (Simons, 2001), past research suggests that most people often resist persuasion by engaging in other options, such as counterarguments, persuasion avoidance, or persuasion negation. Quinn and Wood's (2004) meta-review of research studies on the effectiveness of persuasive messages concluded that forewarnings about persuasive intentional messages may induce resistance. The theory of reactance (Fortuna, 2007) explains that unsuccessful persuasion sometimes occurs because the persuasion process may threaten a person's sense of autonomy and freedom (both psychological and physical).

Persuasive intention has been conceptualized in two different types or strategies - indirect and direct. Direct persuasion is clear and apparent, such as verbal claims about the intended attribute explicitly mentioned in the persuasive communication (e.g., low repair costs in garage advertising). In contrast, indirect persuasion contains verbal or visual claims about the intended attribute through analogy, metaphor, suggestion, or the inclusion of a similar attribute (e.g., instead of low repair cost - high dependability of the garage). Indirect persuasion does not expose its own position and thus may incur less resistance from users (Aleahmad, Balakrishnan, Wong, Fussell, \& Kiesler, 2008). Indirect persuasive messages often make nonliteral claims, using mostly figurative language. For example, the metaphoric advertising message is not stated directly, but only implied through contextual information. Furthermore, compared to direct persuasion that provides clear direction whether or not a person agrees, indirect persuasion does not specify immediate actions for the user and can be less clear in a communicative sense (McQuarrie \& Phillips 2005).

Research on the use of direct and indirect persuasion focused mainly on the effectiveness of both forms of persuasion in advertising (e.g., Aleahmad et al. 2008; McQuarrie \& Phillips 2005), and everyday interpersonal context (e.g., Djikic \& Oatley, 2014; Falbo \& Peplau, 1980; Hanson, Pollard, \& Williams, 1999) of adult population. Thus, the majority of this research has mostly advocated the use of indirect persuasive claims expressed by figurative forms in the context of commercials. 
In contrast, research on the use and effectiveness of direct and indirect strategies in interpersonal contact is less clear. Falbo and Peplau's (1980) model of power strategies assumes that in asymmetrical relationships, such as those between romantic partners, compared to direct persuasive strategies such as Direct Questions or Arguments, a romantic partner may often use more indirect strategies such as Manipulation or Hinting. The model also assumes more frequent use of bilateral or more balanced power relationships that take into account the other side of the interaction, rather than unilateral strategies where convincing does not take into account the persuaded person's perspective in asymmetrical relations.

However, in Falbo and Peplau's (1980) study, adult participants described persuasive strategies only in dating relationships. Several studies have used their typology to describe influence attempts in other kinds of relationships, such as marriage or other types of intimate relationships (e.g., Belk et al., 1988; Butterfield \& Lewis, 2002). In most studies, couples who report higher levels of relational satisfaction also report more frequent use of direct (e.g., Asking, Telling) as opposed to indirect (e.g., Hinting, Withdrawal, or Silence) power strategies (Aida \& Falbo, 1991). The results were less clear in diverse cultural contexts (Belk et al., 1988; Kim \& Wilson, 1994).

Compared to adults, less is known about the use of direct/indirect persuasive strategies used by children and adolescents. Cowan, Drinkard, and MacGavin (1984) reported that, when persuading parents, adolescent females used indirect and unilateral strategies more often, whereas males used direct and bilateral power strategies more often. Gender differences decreased when adolescents presented their way of persuading friends (e.g., both females and males used more bilateral than unilateral strategies). The researchers suggest that gender differences may sometimes be mitigated in friendships, perhaps because power may be perceived as more balanced or shared between best friends (Cowan et al., 1984).

Ohbuchi and Yamamoto (1990) showed that in peer conflict situations, 8- to 12-year-olds use direct strategies more often than indirect ones, with a clear developmental trend of more frequent direct bilateral strategies use with age. They found no gender preferences for a certain type of persuasion strategy bilateral or unilateral, direct or indirect. However, later studies of early persuasive abilities did not compare use of direct or indirect strategies directly. The analysis of the frequency of the use of different persuasive attempts reveals a general trend. Weiss and Sachs' (1991) study of preschool children's persuasive strategies showed that with increasing age, children used a higher number of persuasive proposals that were connected with positive offers (like an Offer of Gifts, Favors, or Bargain). Direct strategies (like Bargain, Simple Request, or Reason) were in the most frequently used $(7 \%-15 \%$ of all persuasive appeals), while indirect strategies (like thought manipulation and hint) were least likely to be used $(2.5 \%$ and $1.4 \%$ of all persuasive statements) by children in a persuasive play context. Further 
research by Bartsch, Wright, and Estes (2010), based on two-year language samples of four 3-5 year-old children selected from the CHILDES base, showed that preschoolers used limited sets of persuasive tactics during everyday communication with parents. For example, they used mostly positive, direct tactics such as Commanding, Protesting, Affirming, Questioning, and Explaining, and only rarely used one indirect strategy - Hinting or Suggesting. The analysis showed that, with age, children were increasingly using only one direct argumentation-based explanatory strategy.

\section{Persuasion Abilities and Socio-cognitive Development}

To date, little is known about the relations between the development of social cognition and the persuasive abilities of preschool and school-age children. For example, Bartsch and London's (2000) study of 4- to 12-year-olds showed that with increasing sensitivity to the mental states of others, most 6-year olds learned to adapt their arguments to the persuadee's beliefs. Within story format situations, children used belief information expressed by the protagonist to select appropriate persuasive arguments. Subsequent direct comparison between first order understanding of false belief and choice of persuasive proposals that refer to the beliefs of the person to be persuaded showed significant, however weak, correlations in the 3- to 5-year-old, but not in the 6- to 7-year-old, age groups (Bartsch et al., 2007). Slaughter et al. (2013) found that 3- to 8-year-old children with higher mental state understanding responded with more diverse variety of persuasive proposals, and in particular with direct, positively valenced arguments that offered an attractive incentive or a favourable spin on the situation (i.e., reward).

Research conducted with older children showed that the linguistic complexity of persuasive writing by 9- to 11-year-olds' social problem solving strategies was connected with their perspective taking, interpersonal understanding, and relational management abilities (Dray, Selman, \& Schultz, 2009). Studies with 8- to 12-year-olds have also found positive associations between rhetorical competencies and the ability to adapt to listeners and coordinate multiple views or perspectives (Kline \& Clinton, 1998). Developmental studies on argumentation skills also show that interpersonal conflict with peers improved in preschool(Rytel, 2009), and school-aged children (Stein \& Albro, 2001). For example, older children formed longer arguments and constructed detailed, coherent rationales to defend a favored position or compromise (Stein \& Albro, 2001). However, research suggests that young adolescents may continue to have challenges in counterargument understanding and effective use of evidence as argumentation objectives (Kuhn, Zillmer, Cornwell, \& Zavala, 2013). For example, past research shows that some adolescents often ignore an opponent's point of view or perspective and thus continue to either push forward and introduce a new idea or continue with a previous point of view (Kuhn et al., 2013). Kuhn et al., (2013) suggest that this 
finding may indicate that the difficulty with effective argumentation may be related to the ability to decide whether to use indirect argumentation strategies to achieve personal goals.

Despite the aforementioned research, relatively little is known about the role children's understanding of mental states play in the development of persuasive communication. Published reviews of ToM development in middle childhood define more advanced ToM development as the discovery of the interpretative nature of mind that helps us to understand the property of actions that leads people to call them purposeful actions (Lagattuta, Sayfan, \& Blattman, 2010; Malle, 2010). For example, such abilities include recursive reasoning (Miller, 2012), understanding certainty (Pillow, 2012), controllability (Flavell, Green, \& Flavell, 1998), and intentionality of thinking. For the present study, we focused on the ability to understand intentionality of behaviour as we considered it an important dimension of advanced ToM development (Astington, 2001; Lagattuta, Kennedy, Hjortsvang, Goldfasrb, \& Tashjian, 2015). Following Malle and Knobe (1997), we used the term "intention" as a concept that is embedded in a broader folk theory of intentionality - more applied to a sequence of actions carried out with a particular goal in mind (Malle, Moses, \& Baldwin, 2001). From a developmental perspective, intentionality understanding gradually develops to more advanced cognitive levels around the ages of 5 to 7 years, and continues to develop throughout childhood and adolescence (Malle, 2010; Mull \& Evans, 2010; Schult, 2002).

In particular, Mull and Evans' (2010) built on Malle and Knobe's (1997) folk concept of intentionality and indicated that intentionality is a complex, hierarchical term that consists of five hierarchical core components (belief, desire, intention, awareness, and skill). For example, belief and desire are necessary conditions for attributions of intention and, given an intention, skill and awareness are necessary conditions for attributions of intentionality. Given this definition, Mull and Evans (2010) assumed that action intentionality understanding refers to physical acts such as throwing a tennis ball. That is, to understand that a person throws a ball intentionally means that the ball-thrower would hold the belief and desire to throw the ball.

In contrast, the act of dropping a ball could be considered either an accidental or an intentional act. To discern this difference, the protagonist must have the skill to perform an act if the act is to be considered intentional and, finally, the protagonist must recognize the performance of the action. In particular, Mull and Evans (2010) showed that 3- to 9 year-old children's explanations of the intentionality of characters' behaviours differed from adults in their level of skill understanding and intentionality awareness. Mull and Evans found that when early school age children focused on the protagonists' desires and actions, 8- to 9 -year-olds and adults were more likely to reference to more advanced aspects of intentionality - the protagonists' awareness and skills. 
Research shows that intentionality understanding (and mostly the discovery of unintentional acts) occurs in many social situations, such as the detection of faux pas (Banerjee, Watling, \& Caputi, 2011; Baron-Cohen, O'Riordan, Stone, Jones, \& Plaisted, 1999) and the assignment of blame in moral judgments (Talwar, Gomez-Garibello, \& Shariff, 2014). Recognition of faux pas, or social gaffes that involve unintentional insults or psychological injuries (Baron-Cohen et al., 1999), imposes demands on advanced cognitive and affective ToM domains and intentionality understanding. Faux pas comprehension requires understanding that there is a difference between a speaker's knowledge state and that of their listener, and an appreciation of the emotional impact of a statement on the listener. Faux pas comprehension requires understanding that in result of a social gaffe, the listener's feelings have been not intentionally hurt by the speaker (Henry, Phillips, Ruffman, \& Bailey, 2013).

Given that young people's developing intentionality understanding has consequences for understanding social and moral conduct (Banerjee et al., 2011; Güroğlu, van den Bos, \& Crone 2009; Leslie, Knobe, \& Cohen, 2006; Myers \& Liben, 2008), intentionality understanding may also help children to view persuasion as a deliberate, intentional communicative activity aimed to alter another person's thinking and behaviour. Accordingly, the present study aimed to explore the relations between school age children's persuasive abilities and intentionality understanding.

For this study, we defined children's persuasive abilities as the ability to use the direct or indirect persuasive strategies. That is, to describe the persuasive skills of participants, we followed the detailed system of persuasive strategies proposed by Waiss and Sachs (1991). Their proposal was based on Falbo and Peplau's (1980) classification of direct/indirect and bilateral/unilateral persuasion. Given previous research findings (Bartsch et al., 2010; Ohbuchi, \& Yamamoto, 1990; Weiss, \& Sachs 1991), we expected that compared to younger participants, older child participants would use more direct bilateral strategies.

Past research shows that children rarely use indirect strategies, mostly because they are related with the use of nonliteral language and the ability to differentiate what is said from what is meant or intended (Sopory \& Dillard, 2002). Recent findings from developmental communicative studies suggest that the ability to understand and use nonliteral language develops extensively in middle childhood (e.g., Bernicot, Laval, \& Chaminaud, 2007; Read \& Szokolszky, 2016). Based on this assumption, our first goal was to check whether the task of persuading parents (asymmetric power relationships) will encourage children to use more indirect persuasive strategies as compared to the task of persuading peers (symmetric power relationship).

Furthermore, given that past research suggests persuasion requires the understanding that to change the behaviour of another person, one must first intentionally change his/her beliefs and attitudes, the ability to persuade should, 
then, require a deeper understanding of the intentionality of behaviour. Building upon this assumption, the second goal of our study was to investigate the relations between children's understanding of intentionality and their persuasive skills. We assumed that the child's understanding of the intentional nature of a persuadee's action may have a differential influence on the child's persuasive direct/indirect, bilateral/unilateral communication strategies. We expected stronger relations for more advanced bilateral than unilateral and indirect than direct persuasion strategies. Finally, our decision to focus on children between 5 and 7 years of age was based on previous studies that suggest that most children develop persuasive, rhetorical skills and intentionality understanding during this time (Bartsch \& London, 2000; Kline \& Clinton, 1998; Mull \& Evans, 2010, Slaughter et al., 2013).

\section{Method}

\section{Participants}

The present study involved 95 children: 28 five-year-olds ( 12 female and 16 male, ranged from 5 years and 1 month to 5 yearsand 9 months, $M=5$ years and 3 months), 37 six-year-olds (17 male and 20 female, ranged from 6 years to 6 years and 8 months, $M=6$ years and 6 months), 30 seven-year-olds (18 male and 12 female, ranged from 7 years to 7 years and 11 months, $M=7$ years and 6 months). The research was performed in a mid-sized city within Southern Poland. Children participated obtaining their parents' informed consent. This consent was obtained by the first author in meeting with parents and teachers in two nurseries or two schools. Based on discussions with the school principals, we selected public kindergartens and schools within the town centre, which was in an area predominantly occupied by middle socioeconomic status (SES) families.

Materials, Procedures, and Scoring. Each child was interviewed individually two times within a two-week period, within a quiet room in the nursery or the school he/she attended. During the first meeting, each child individually completed the persuasion tasks administered by a researcher, followed by an intentionality task in the second. Each meeting lasted about 10-15 minutes.

Persuasion stories. The task involved persuasive arguments between two people (a persuader and a persuadee), based on the basic scheme of persuasive stories proposed by Bartsch et al. (2007). We prepared four illustrated stories where a girl or a boy wanted to convince their parents or peers to go for a trip or play with a selected/preferred toy. The parental and peer attitude was illustrated by a specified belief (e.g., "Mum thinks that ..."). In the task, each child was required to suggest persuasive strategies for the protagonist. Each story contained the protagonist and two other characters - parents (mother and father) or peers (two boy or girl friends). Each story contained two parts. The child was asked to help the protagonist persuade another person in each story section, $\backslash$ by answering 
the questions of "What can X say or do to persuade mum/dad/friend to agree to ...?" and "What else can she/he say or do?" To counterbalance the story order, the story sequence presentation (adult vs. peer; trip vs. toy) was determined on the basis of a proportional distribution of presentation order in each age group. An example of a story is presented in Appendix A.

During the assessment period, the persuasive proposals were first counted. This way, a general number of persuasive proposals (from 0 to 16) was obtained. Secondly, participants' responses were analysed according to the type of persuasive strategy. The classification of strategies was based on a 23-strategy system developed by Weiss and Sachs (1991) and on Falbo and Peplau's (1980) classification system of direct/indirect and bilateral/unilateral persuasion strategies. The final strategy classification system used, with descriptions and examples, is presented in Appendix B.

Transcribed recordings of the interviews were coded by two judges (one graduate and one student researcher) familiar with the task and development of persuasive skills but blind to the purpose of the study (30 interviews were independently coded by both judges). Assessment congruity for the coding of the persuasion strategies showed Cohen's Kappa to vary from .77 to .96. The discrepancies in the coding were discussed until the researchers and the first author arrived at a consensus.

Intentionality understanding task. The intentionality task was based on Mull and Evans' (2010) test procedure. The present study included six stories. We chose Tasks 1 and 2 from the procedure in Mull and Evans' (2010) measures of behaviour intentionality understanding, Tasks 2 and 3 as measures of skill intentionality, and Tasks 1 and 3 as measures of awareness intentionality. In all the tasks, there were illustrated stories presenting two protagonists: one behaving intentionally and the other unintentionally. In each task, children were asked the identification question of "Who meant to do it?" and two explanation questions: "Why do you think it was X?" (Justification A) and "Why do you think it wasn't Y?" (Justification B).

As far as the scoring was concerned, we used an identification and explanation scoring procedure proposed by Mull and Evans (2010). The correct identification of the person that performed the action intentionally was given 1 point. The total range of scores was $0-6$. An adjusted explanation score was created for each intentionality measure and consisted of the number of the appropriate justifications divided by the total of the justifications numbers given by each participant (total range of $0-3$ ).

We also proposed a new, aggregated identification and explanation score, following the idea that the judgments and explanations taken together provide a deeper and more reliable insight into the understanding of children's mental phenomena (Berthoud-Papandropoulon \& Kilcher, 2003; Karmiloff-Smith, 1995). No points were given for incorrect identification or correct identification but 
incorrect justification (which showed not understanding the difference between intentional and unintentional acts). One point was assigned for correct identification and justification that showed understanding the difference between intentional and unintentional acts. Total score could range from 0 to 6 points. The aggregated score can be seen in the example from the story of understanding awareness of intentionality.

In the story, in the first picture Basia goes over the edge of her paper and draws on the table. The researcher says "Remember, Basia was watching TV and didn't see what she was drawing." In the second picture, Sławek goes over the edge of his paper and draws on the table. The researcher says "Slawek was looking at his paper, so he did see what he was drawing". The intentionality identification question was: "Who meant to draw on the table, Basia or Sławek?" and two justification questions were: "Why do you think it was Basia/Sławek?" and "Why don't you think it was Basia/Sławek?"

Example of the proper answer presented by six year old participant: Identification - Basia. First justification response: "Because she was looking up, she couldn't see." Second justification response: "Because he was looking down here, and he could see."

Transcribed recordings of 30 interviews were coded independently by two competent judges (one graduate and one student researcher) familiar with the task but blind to the purpose of the study (30 interviews were coded independently by each of them). Assessment congruity between judges was $95 \%$. Coding differences were discussed and eliminated.

Expressive language ability. Following past studies that controlled for the possibility of a confounding variable, such as general language ability (e.g., Slaughter et al., 2013), the present study included the Language Production Index (LP Index). That is, we calculated the total word count for each participant to provide a control for expressive language ability.

\section{Results}

Initial analysis of the participants' responses showed that $77 \%$ of participants gave at least one proposal in all stories about persuading a parent and $72 \%$ of participants created persuasive statements in all peer stories. The mean number of all proposals was 11.01 out of possible 16. Participants created 1068 persuasive proposals in total; $45.41 \%$ of them were direct bilateral (like Reasoning or Compromise), $38.11 \%$ direct unilateral (like Simple Request or Plead), $12.07 \%$ indirect bilateral (like Hinting or Guarantee) and only $4.4 \%$ indirect unilateral (like Politeness). Descriptive statistics for all measures are presented in Tables 1 and 2.

\section{Development of Persuasive Strategies}

At first, we tested whether the type of persuasive strategies adopted by participants differed according to strategy type: Directness (2), Laterality (2), 
Table 1. Descriptive Statistics for the Persuasive Communication, Intentionality Understanding Tasks, and Language Production Index

\begin{tabular}{lcccc}
\hline Variable & Min & Max & M & SD \\
\hline $\begin{array}{l}\text { Persuasive communication } \\
\quad \text { Number of persuasive proposals }\end{array}$ & 0.00 & 16.00 & 11.01 & 4.42 \\
$\begin{array}{l}\text { Persuasive strategies } \\
\quad\end{array}$ & & & \\
$\quad$ Direct bilateral & 0.00 & 16.00 & 5.10 & 4.61 \\
$\quad$ Direct unilateral & 0.00 & 15.00 & 4.28 & 3.74 \\
$\quad$ Direct Total & 0.00 & 16.00 & 9.38 & 4.34 \\
$\quad$ Indirect bilateral & 0.00 & 12.00 & 1.35 & 2.36 \\
$\quad$ Indirect unilateral & 0.00 & 8.00 & 0.49 & 1.33 \\
$\quad$ Indirect Total & 0.00 & 12.00 & 1.85 & 2.58 \\
Intentionality understanding & & & & \\
$\quad$ Identification score & 0.00 & 6.00 & 4.48 & 1.39 \\
$\quad$ Explanation score & 0.00 & 3.00 & 2.03 & 0.78 \\
$\quad \begin{array}{l}\text { Identification-Explanations } \\
\text { Aggregated Scores }\end{array}$ & 0.00 & 6.00 & 3.92 & 1.55 \\
Language production index LP & 202.00 & 2031.00 & 578.10 & 346.59 \\
\hline
\end{tabular}

Table 2. Descriptive Statistics for the Persuasive Communication Strategies Use

\begin{tabular}{lcccc}
\hline Strategy & Min & Max & $\boldsymbol{M}$ & $\boldsymbol{S D}$ \\
\hline Reasoning-arguments & 0.00 & 14.00 & 3.92 & 3.96 \\
Simple request & 0.00 & 13.00 & 2.82 & 3.02 \\
Guarantee & 0.00 & 8.00 & 0.92 & 1.79 \\
Compromise & 0.00 & 7.00 & 0.76 & 1.46 \\
Simple statement & 0.00 & 11.00 & 0.67 & 1.79 \\
Mitigated simple request & 0.00 & 7.00 & 0.42 & 1.09 \\
Politeness and personal favours & 0.00 & 8.00 & 0.31 & 1.13 \\
Emotion agent & 0.00 & 12.00 & 0.28 & 1.42
\end{tabular}




\begin{tabular}{|c|c|c|c|c|}
\hline Plead & 0.00 & 4.00 & 0.21 & 0.65 \\
\hline Bargaining & 0.00 & 3.00 & 0.18 & 0.51 \\
\hline Reasoning-counterarguments & 0.00 & 2.00 & 0.15 & 0.39 \\
\hline Fait accompli & 0.00 & 5.00 & 0.09 & 0.54 \\
\hline Assertion & 0.00 & 3.00 & 0.07 & 0.39 \\
\hline Force & 0.00 & 2.00 & 0.03 & 0.22 \\
\hline Threat & 0.00 & 1.00 & 0.02 & 0.14 \\
\hline Why? challenge & 0.00 & 1.00 & 0.01 & 0.10 \\
\hline Rebellion & 0.00 & 1.00 & 0.01 & 0.10 \\
\hline Deceit & 0.00 & 1.00 & 0.01 & 0.10 \\
\hline Hinting & 0.00 & 1.00 & 0.01 & 0.10 \\
\hline Thought manipulation & 0.00 & 1.00 & 0.01 & 0.10 \\
\hline Indirect question & 0.00 & 1.00 & 0.01 & 0.10 \\
\hline Emotion target & 0.00 & 1.00 & 0.01 & 0.10 \\
\hline Appeal to higher authority & 0.00 & 0.00 & 0.00 & 0.00 \\
\hline No persuasion & 0.00 & 16.00 & 3.82 & 4.01 \\
\hline Reality change & 0.00 & 8.00 & 1.00 & 1.68 \\
\hline
\end{tabular}

Note. $\%$ = percentage of all proposals presented by researched children

and Persuaded Person (2) as within-subject factors. The repeated-model ANOVA showed a significant effect of directness, $F(1,94)=93.92, p<0.001, \eta^{2}=0.50$, and persuaded person, $F(1,94)=121.04, p<0.001, \eta^{2}=0.56$, but not of laterality, $F(1,94)=1.93, p=0.167, \eta^{2}=0.02$. We found a significant Directness $\times$ Laterality interaction, $F(1,94)=5.77, p=0.018, \eta^{2}=0.06$, as well as a significant Directness $\times$ Person interaction, $F(1,94)=109.69, p<0.001, \eta^{2}=0.54$, but not significant interactions of laterality and person, $\mathrm{F}(1,94)=0.21, \mathrm{p}=.647, \eta^{2}<.01$, and of directness, laterality, and person, $F(1,94)=0.05, p=0.817, \eta^{2}<0.01$. Subsequent analysis was performed by pairwise comparison with adjustment for multiple comparisons (last significant difference, LSD). The analysis of the effect of directness showed that children used more direct $(M=1.40, S E=0.06)$ than indirect $(M=0.45$, $S E=0.07)$ strategies. Participants proposed more persuasive proposals in stories with child-parent character interaction $(M=1.42, S E=0.06)$ than with child-peer interaction $(M=0.43, S E=0.06)$. Analysis of interaction of directness and laterality showed that participants used indirect bilateral $(M=0.67, S E=0.12)$ strategies 
more often than indirect unilateral ones $(M=0.23, S E=0.05)$. Analysis of the Directness $\times$ Person interaction showed that persuading parent character participants used direct strategies $(M=2.36, S E=0.12)$ more often than indirect ones $(M=0.45$, $S E=0.07)$. This difference was not significant for child-peer interaction.

Adding the age factor to the analysis showed no significant effects or interactions. We decided to perform a repeated model ANOVA for Directness (2) and Laterality (2) as within-subject factors and Age (3) as a between-subject factor. Analysis showed a significant effect of directness, $F(1,92)=166.61, p<0.001, \eta^{2}=0.64$, a significant effect of laterality, $\mathrm{F}(1,92)=5.07, \mathrm{p}=.027, \eta^{2}=.05$, and a significant effect of age, $F(2,92)=6.11, p=0.003, \eta^{2}=0.12$. We found a significant interaction of laterality and age, $F(2,92)=5.59, p=0.005, \eta^{2}=0.11$, but not a significant interaction of directness and age, $F(2,92)=1.49, p=0.230, \eta^{2}=0.03$, and nonsignificant interactions of laterality, directness, and age, $F(2,92)=2.28, p=0.107, \eta^{2}=0.05$. Subsequent pairwise comparison with adjustment for multiple comparisons (LSD) of the effect of laterality showed that children used more bilateral $(M=3.21, S E=0.22)$ than unilateral strategies $(M=2.37, S E=0.20)$. Subsequent analysis of interaction of laterality and age showed that only the eldest, 7-year-old children used more bilateral $(M=4.42, S E=0.39)$ than unilateral $(M=1.93, S E=0.36)$ strategies. Bilateral strategies were also proposed more often by 7 -year-olds than younger groups, 6-year-olds $(M=3.27, S E=0.36)$ used bilateral strategies more often than 5-year-olds $(M=1.95, S E=0.40)$.

\section{Persuading and Intentionality Understanding}

To verify the relationships between persuasive skills and intentionality understanding, we computed Spearman rho and partial correlation tests controlled for age and language production between performance in intentionality and persuasion tasks (see Table 3). Correlations demonstrated that the better children understood intentionality (aggregated score), the more often they used direct bilateral, $r(95)=0.28, p=0.005$, and indirect bilateral, $r(95)=0.22, p=0.03$, strategies. The use of indirect bilateral strategies was also connected with the ability to explain intentionality of the character behavior, $r(95)=0.21, p=0.03$. All correlations were moderate.

\section{Discussion}

The present study showed that, although the participating 5- to 7-year-old children did not differ in the ability to use direct or indirect persuasion strategies, they differed in their use of bilateral as compared with unilateral persuasive strategies. In general, participants proposed more persuasive proposals in stories with child-parent asymmetrical power interactions than with child-peer symmetrical power interactions. However, Falbo and Peplau's (1980) model assumes that the asymmetrical power relations should encourage persons to more frequently use 
Table 3. Spearman Correlations and Partial Correlations (Controlling for Age and Language Production Index) Among Persuasive Communication and Intentionality Understanding Tasks Scores

\begin{tabular}{lccc}
\hline Persuasive Communications & $\begin{array}{c}\text { Identification } \\
\text { score }\end{array}$ & $\begin{array}{c}\text { Explanation } \\
\text { score }\end{array}$ & $\begin{array}{c}\text { Identification- } \\
\text { Explanations } \\
\text { Aggregated } \\
\text { Scores }\end{array}$ \\
\hline Direct total & $0.17(0.15)$ & $0.14(0.12)$ & $0.25^{*}\left(0.22^{*}\right)$ \\
$\quad$ Direct bilateral & $0.19(0.18)$ & $0.14(0.12)$ & $0.28^{* *}\left(0.28^{* *}\right)$ \\
$\quad$ Direct unilateral & $0.02(-0.04)$ & $0.02(0.00)$ & $-0.06(-0.08)$ \\
Indirect total & $0.08(0.05)$ & $0.10(0.06)$ & $0.14(0.04)$ \\
$\quad$ Indirect bilateral & $0.15(0.10)$ & $0.21^{*}(0.16)$ & $0.22^{*}(0.08)$ \\
$\quad$ Indirect unilateral & $-0.01(-0.08)$ & $-0.06(-0.16)$ & $0.02(-0.07)$ \\
\begin{tabular}{l} 
Number of persuasive proposals \\
\hline$* p<0.05$.
\end{tabular} & $0.17(0.14)$ & $0.18(0.13)$ & $0.25^{*}\left(0.23^{*}\right)$ \\
\hline${ }^{* *} p<0.01$. & & & \\
$* * * 00.001$. & & &
\end{tabular}

indirect rather than direct strategies. Ohbuchi and Yamamoto (1990) showed that, in peer conflict situations, school-aged children (8- to 12-year-olds) used more direct than indirect persuasive strategies.

As Weiss and Sachs' (1991) study of preschool children implied and our study showed, 5- to 7 year-old participants used indirect proposals less often than direct ones. More specifically, in child-parent persuasion stories, participants used more direct than indirect persuasive strategies, while this difference was not significant for child-peer interactions. Perhaps in asymmetric interactions, children refer to the direct unilateral and bilateral strategies such as Reasoning and Targeted Questioning because, compared to indirect strategies, direct strategies were more transparent in the indication of communicative intention.

The present study suggests that children were more focused on this communicative aspect. One reason may be that, compared to direct persuasion, the participating children found indirect or nonliteral language forms of persuasion more difficult (Sopory \& Dillard, 2002). During middle childhood, children extensively learn how to use nonliteral language (e.g., Bernicot et al., 2007; Read \& Szokolszky, 2016) and perhaps persuasive situations encourage children to use new forms of communication. Children also might find it challenging to 
express their thoughts and emotions through language and use indirect forms of persuasion. Interestingly, our study found that when 5- to 7-year-old children used indirect strategies, they chose more difficult, but also more effective bilateral (e.g., Guarantee) than unilateral strategies (e.g., Politeness, Personal Favors).

The present study showed that, compared to the younger children, the older 7-year-old participants used bilateral strategies more often than unilateral strategies. This finding may suggest a growing sensitivity to the other person's beliefs and an ability to understand and appreciate another person's way of perceiving or interpreting social situations. As Talwar et al. (2014) found with adolescents' on-line moral evaluations, Stein and Albro (2001) also found that sensitivity to the other person's point of view or perspective in conflict situations is a useful negotiation skill and may also help children to compromise with others and develop mutually beneficial solutions and better social relationships (Stein \& Albro, 2001; Yeates et al.,1991).

The present data also showed that, compared to younger children, the older children in our study were more likely to use advanced direct bilateral persuasive strategies like Reasoning or Compromise. This result was consistent with Stein and Albro's (2001) idea that negotiation skills are a developmentally more advanced set of skills, all which are crucial for solving interpersonal conflicts. The present results also support Yeates et al.'s (1991) model of interpersonal negotiation strategies where a higher reciprocal level of development is connected with attempts to satisfy the needs of both participants by Negotiation and Compromise.

In contrast to the Yeates et al. (1991) study where the ability to propose Negotiation and Compromise was mostly observed in early-adolescents, in this study, we investigated early, simple forms of Bargain and Compromise in younger school-age groups. Within the process of argumentation, this result can broaden the theoretical explanation as to why younger children tend to mostly focus on the objective reasons and desires of someone other than themselves. Moreover, past research suggests that older school-aged children learn to gradually increase their skills and focus on subjective reasons, personal plans, and view-points, as they continue to plan actions and explain the behaviour of other people (Malle, 2010; Pillow, 2012).

To address our second goal, which was to examine the relations between children's persuasive proposals and understanding of intentionality, the present data showed that when a persuader developed an understanding of the intentionality, they focused on the use of bilateral direct and indirect strategies as the strategies increased in intensity. Perhaps this finding reflected that some children may realize that they should attempt to persuade another person with an appropriate strategy. Understanding the intentionality of actions could result in a focus on the most advanced argumentation strategies and possibly lead to their intentional use when the child wants to achieve a specific goal. 
It is also possible that the discovery of more advanced aspects of intentionality as well as the realization of the difference between unintentional and intentional behavior may help children to learn the skills of effective persuasion. Our result suggests that, as children develop, they may also increase their focus on the perspective of the person being persuaded. Thus, as children become older and gain more experience with social communication, they may also develop the ability to create more persuasive proposals that relate to the persuadee's beliefs and use more efficient - bilateral - strategies (e.g., Kline \& Clinton, 1998).

In sum, the present results suggest that young Polish school-aged children's direct persuasive strategies reflected positive relations between intentionality understanding and greater communication effectiveness of direct persuasion strategies. It is possible, however, that the relation between persuasion skills and intentionality understanding is not specific, but may suggest that the development of advanced social understanding starts to develop in middle childhood (Miller, 2012; Pillow, 2012). Further studies could explore whether the relations between children's intentionality understanding and persuasion is associated to advanced ToM development and persuasive skills.

Limitations of the current study include the focus on a cross-sectional, correlational design and studying cognitive mental states as opposed to emotional or moral states. Finally, the present study explored the role of vocabulary ability only. Future studies need to include a longitudinal design with more comprehensive measures of verbal and communicational abilities (e.g., use and understanding of nonliteral language forms), working memory, and more diverse use of social-understanding tasks.

Given that Stein and Albro (2001) showed that people's emotions changed the majority of argumentation within interpersonal conflict, future studies should focus on the emotional context of the persuasion process within children and adolescents. Within the present study, the rare use of emotional argumentation strategies was influenced in part by the structure of the proposed situation, as the present study's focus was on the protagonist's beliefs. Further research should also focus on finding other developmental conditions of argumentative and persuasive skills that are connected with ToM development. That is, future studies should explore children's understanding of the interpretative nature of mind and emotional knowledge (Slaughter et al., 2013).

The main message of this study suggests that children's knowledge of persuasive and argumentative skills continues to develop in linguistic complexity. The study showed that children formulated effective arguments and were sensitive to the perspective of the other person. Such a finding holds important consequences for the development of the connections between social understanding and children's peer relations (Miller, 2012).

The exploration of the development of persuasive conversation among children is a promising forum for the study of psychological awareness in situations 
in which children are well-motivated to utilize their knowledge of other people's mental states (Bartsch et al., 2010). The present findings have practical implications that can help us to develop a better understanding of the early argumentative and negotiation skills for children and adolescents. For example, educational programmes that teach young people to develop effective persuasive skills such as psychological awareness, mindreading strategies, and different communication forms (literal and nonliteral form) may help youth to learn to effectively communicate with their peers and teachers (Crowell \& Kuhn, 2014).

\section{References}

Aida, Y. \& Falbo, T. (1991). Relationships between marital satisfaction, resources, and power strategies. Sex Roles, 24 (1), 43-56.

Aleahmad, T., Balakrishnan, A.D., Wong, J., Fussell, S.R., \& Kiesler, S. (2008). Fishing for sustainability: The effects of indirect and direct persuasion. In M. Czerwinski, A. Lund, \& D. Tan (Eds.), Extended Abstracts on Human Factors in Computing Systems (pp. 3021-3026). New York, NY: ACM.

Astington, J.W. (2001). The paradox of intention: Assessing children's meta-representational understanding. In B. Malle, L. Moses, \& D. Baldwin (Eds.), Intentions and Intentionality: Foundations of Social Cognition (pp. 85-104). Cambridge, MA: MIT Press.

Banerjee, R., Watling, D., \& Caputi, M. (2011). Peer relations and the understanding of faux pas: Longitudinal evidence for bidirectional associations. Child Development, 82 (6), 1887-1905.

Baron-Cohen, S., O’Riordan, M., Stone, V., Jones, R., \& Plaisted, K. (1999). Recognition of faux pas by normally developing children with asperger syndrome or high-functioning autism. Fournal of Autism and Developmental Disorders, 29(5), 407-418.

Bartsch, K. \& London, K. (2000). Children's use of mental state information in selecting persuasive arguments. Developmental Psychology, 36 (3), 352-365.

Bartsch, K., London, K., \& Campbell, M.D. (2007). Children's attention to beliefs in interactive persuasion tasks. Developmental Psychology, 43 (1), 111-120.

Bartsch, K., Wright J., \& Estes, D. (2010). Young children's persuasion in everyday conversation: Tactics and attunement to others' mental states. Social Development, 19 (2), 394-416.

Belk, S.S., Snell, W.E., Garcia-Falconi, R. Hernandez-Sanchez, J.E., Hargrove, L., \& Holtzman, W.H. (1988). Power strategy use in the intimate relationships of women and men from Mexico and the United States. Personality and Social Psychology Bulletin, 14 (3), 439-447.

Bernicot, J., Laval, V., \& Chaminaud, S. (2007). Nonliteral language forms in children: in what order are they acquired in pragmatics and metapragmatics? Journal of Pragmatics, 39 (12), 2115-2132. 
Berthoud-Papandropoulou, I. \& Kilcher, H. (2003). Is a false belief statement a lie or a truthful statement? Judgments and explanations of children aged 3 to 8. Developmental Science, 6 (2), 173-177.

Butterfield, R.M. \& Lewis, M.A. (2002). Health-related social influence: A social ecological perspective on tactic use. Journal of Social and Personal Relationships, 19 (4), 505-526.

Cowan, G., Drinkard, J., \& MacGavin, L. (1984). The effects of target, age, and gender on use of power strategies. Fournal of Personality and Social Psychology, 47 (6), 1391-1398.

Crowell, A. \& Kuhn, D. (2014). Developing dialogic argumentation skills: A three-year intervention study. Journal of Cognition and Development, 15 (2), 363-381.

Djikic, M. \& Oatley, K. (2014). The art in fiction: From indirect communication to changes of the self. Psychology of Aesthetics, Creativity, and the Arts, $8(4), 498-505$.

Dray, A.J, Selman, R.L., \& Schultz, L.H. (2009). Communicating with intent: A study of social awareness and children's writing. Journal of Applied Developmental Psychology, 30 (2), 116-128.

Falbo, T. \& Peplau, L.A. (1980). Power strategies in intimate relationships. Journal of Personality and Social Psychology, 38 (4), 618-628.

Flavell, J.H., Green, F.L., \& Flavell, E.R. (1998). The mind has a mind of its own: Developing knowledge about mental uncontrollability. Cognitive Development, $13(1), 127-138$.

Fortuna, P. (2007). Obrona przed wplywem telewizji. Lublin: Towarzystwo Naukowe KUL.

Griffin, E.A. (2011). A First Look at Communication Theory (8th ed). New York, NY: McGraw-Hill Higher Educationl.

Güroğlu, B., van den Bos, W., \& Crone, E.A. (2009). Fairness considerations: Increasing understanding of intentionality in adolescence. Fournal of Experimental Child Psychology, 104 (4), 398-409.

Hanson, E.J., Pollard, G.D., \& Williams, Ch.M., (1999). Persuasion tactics used by college age females on college age males. Report available online from: ERIC:http://www.eric.ed.gov/contentdelivery/servlet/ ERICServlet?accno=ED453567

Henry, J.D., Phillips, L.H., Ruffman, T., \& Bailey, P.E. (2013). A meta-analytic review of age differences in theory of mind. Psychology of Aging, 28 (3), 826-839.

Karmiloff-Smith, A. (1995). Beyond Modularity. A Developmental Perspective on Cognitive Science. Cambridge, MA: MIT Press.

Kim, M.S. \& Wilson, S.R. (1994). A cross-cultural comparison of implicit theories of requesting. Communication Monographs, 61 (3), 210-235.

Kline, S.L. \& Clinton, B.L. (1998). Developments in children's persuasive message practices. Communication Education, 47 (2), 120-136. 
Kuhn, D., Zillmer, N., Crowell, A., \& Zavala, J. (2013). Developing norms of argumentation: Metacognitive, epistemological, and social dimensions of developing argumentive competence. Cognition and Instruction, 31 (4), 456-496.

Lagattuta, K.H., Kramer, H. J., Kennedy, K., Hjortsvang, K., Goldfasrb, D., \& Tashjian, S. (2015). Beyond Sally's missing marble: Further development in children's understanding of mind and emotion in middle childhood. Advances in Child Development and Behavior, 48, 185-217.

Lagattuta, K.H., Sayfan, L., \& Blattman, A.J. (2010). Forgetting common ground: Six- to seven-year-olds have an overinterpretive theory of mind. Developmental Psychology, 46 (6), 1417-1432.

Leslie, A.M., Knobe, J., \& Cohen, A. (2006). Acting intentionally and the side-effect effect: 'Theory of mind' and moral judgment. Psychological Science, 17 (5), 421-427.

Malle, B.F. (2010). Intentional action in folk psychology. In T. O'Connor, \& C. Sandis (Eds.), A Companion to the Philosophy of Action (pp. 357-365). Chichester, UK: Willey-Blackwell.

Malle, B.F. \& Knobe, J. (1997). The folk concept of intentionality. Fournal of Experimental Social Psychology, 33 (2), 101-121.

Malle, B.F., Moses, L.J., \& Baldwin, D.A. (2001). Introduction: The significance of intentionality. In B.F. Malle, L.J. Moses, \& D.A. Baldwin (Eds.), Intentions and Intentionality: Foundations of Social Cognition (pp. 1-24). Cambridge, MA: MIT Press.

McQuarrie, E. \& Phillips B.J. (2005). Indirect persuasion in advertising: How consumers process metaphors presented in pictures and words. fournal of Advertising, 34 (2), 7-20.

Miller, S.A. (2012). Theory of Mind Beyond the Preschool Years. New York, NY: Psychology Press.

Mull, M.S. \& Evans, E.M. (2010). Did she mean to do it? Acquiring a folk theory of intentionality. Journal of Experimental Child Psychology, 107 (3), 207-228.

Myers, L.J. \& Liben, L.S. (2008). The role of intentionality and iconicity in children's developing comprehension and production of cartographic symbols. Child Development, 79 (3), 668-684.

Ohbuchi, K.I. \& Yamamoto, I. (1990). Power strategies of Japanese children in interpersonal conflict: Effects of age, gender and target. Fournal of Genetic Psychology, 151 (3), 3, 349-360.

Pillow, B.H. (2012). Children's Discovery of the Active Mind. Phenomenological Awareness, Social Experience, and Knowledge About Cognition. New York, NY: Springer.

Quinn, J.M. \& Wood, W. (2004). Forewarnings of influence appeals. In E.S. Knowles \& J.A. Linn (Eds.), Resistance and Persuasion (pp. 193-213). New Jersey, NJ: Lawrence Erlbaum \& Associates 
Read C. \& Szokolszky, A. (2016). A developmental ecological study of novel metaphoric language use. Language Sciences, 53 (Part A), 86-98.

Rytel, J. (2009). Arguing to persuade and arguing to explore in preschoolers' narrative discourse. Psychology of Language and Communication, 13 (1), 21-38.

Schult, C.A. (2002). Children's understanding of the distinction between intentions and desires. Child Development, 73 (6), 1727-1747.

Searle, J.R. (1983). Intentionality: An Essay in the Philosophy of Mind. Cambridge, MA: Cambridge University Press.

Simons, H.W. (2001). Persuasion in Society. Thousand Oaks, CA: Sage Publications.

Slaughter, V., Peterson C.C., \& Moore C. (2013). I can talk you into it: Theory of mind and persuasion behavior in young children. Developmental Psychology, 49 (2), 227-231.

Sopory, P. \& Dillard, J.P. (2002). Figurative language and persuasion. In: J.P. Dillard \& M. Pfau (Eds.), The Persuasion Handbook: Developments in Theory and Practice (pp. 407-426). Thousand Oaks, CA: Sage Publications.

Stein, N.L. \& Albro, E.R. (2001). The origins and nature of arguments: Studies in conflict understanding, emotion, and negotiation. Discourse Processes, $32(2-3), 113-133$.

Talwar, V., Gomez-Garibello, C., \& Shariff, S. (2014). Adolescents' moral evaluations and ratings of cyberbullying: The effect of veracity and intentionality behind the event. Computers in Human Behavior, 36, 122-128.

Tokarz, M. (2006). Argumentacja, perswazja, manipulacja. Wyklady z teorii komunikacji. Gdańsk: Gdańskie Wydawnictwo Psychologiczne.

Weiss, D.M. \& Sachs, J. (1991). Persuasive strategies used by preschool children. Discourse Processes, 14 (1), 55-72.

Yeates, K.O., Schultz, L.H., \& Selman, R.L. (1991). The development of interpersonal negotiation strategies in thought and action: A social-cognitive link to behavioral adjustment and social status. Merrill-Palmer Quarterly, 37 (3), 369-405.

\section{Appendix A}

Example of the Story Used in the Persuasive Task:

Today is Saturday. Mum and Dad have a free day and wonder what they can do together. Maybe go for an ice cream? Basia really, really wants to go to the amusement park today.

Q: How can you help Basia to persuade the parents to make a decision? 
This is Basia's mother. Mum said that there will be a lot of people at the amusement park. She said "Basia, this is a bad idea. I think that there will be a lot of people at the amusement park".

Q1: What can Basia say or do to persuade her mum to agree to go to the amusement park?

Q2: What else can she say or do?

Look, this is Basias' father. Dad thinks that there will be a lot of noise at the amusement park. He said "Basia, this is a bad idea. I think that at the amusement park there will be a lot of noise".

Q1: What can Basia say or do to persuade her dad to agree to go to the amusement park?

Q2: What else can she say or do?

\section{Appendix B}

Direct and Indirect Persuasive Strategies Coding Criteria. Categories with Description.

\begin{tabular}{|c|c|c|c|}
\hline Group, Category & $\begin{array}{l}\text { Persuasive } \\
\text { Strategy }\end{array}$ & Description & Example \\
\hline \multirow[t]{2}{*}{$\begin{array}{l}\text { Direct } \\
\text { Strategies }\end{array}$} & Bargaining & $\begin{array}{l}\text { Direct indication of } \\
\text { reciprocating favors; } \\
\text { forms of revenge; } \\
\text { mutual exchange. }\end{array}$ & $\begin{array}{l}\text { He can tell his mother } \\
\text { that if she agrees to } \\
\text { go to the amusement } \\
\text { park, he will clean } \\
\text { the room. }\end{array}$ \\
\hline & $\begin{array}{l}\text { Reasoning } \\
\text { (arguments } \\
\text { and counterar- } \\
\text { guments) }\end{array}$ & $\begin{array}{l}\text { Argument use in } \\
\text { order to influence } \\
\text { the other person; } \\
\text { the child does not } \\
\text { just say that "you } \\
\text { need to convince", } \\
\text { but gives a specific } \\
\text { new argument or } \\
\text { counterargument. }\end{array}$ & $\begin{array}{l}\text { In response to the } \\
\text { father's argument, } \\
\text { that the train has } \\
\text { too many small } \\
\text { parts that get lost: } \\
\text { Argument: „but it is } \\
\text { even better than the } \\
\text { old one, and has coal } \\
\text { wagons." } \\
\text { Counter argument: } \\
\text { "He can say that this } \\
\text { is not true, because if } \\
\text { he puts them in the } \\
\text { box and takes them } \\
\text { out only a small part } \\
\text { of the time- they will } \\
\text { not get lost." }\end{array}$ \\
\hline
\end{tabular}




\begin{tabular}{|c|c|c|c|}
\hline & Compromise & $\begin{array}{l}\text { Proposal of giving } \\
\text { up, by both sides } \\
\text { part of their goals } \\
\text { to achieve other } \\
\text { important objectives. }\end{array}$ & $\begin{array}{l}\text { She may say, that } \\
\text { at first they may go } \\
\text { wherever she wants, } \\
\text { and then to the play } \\
\text { centre. }\end{array}$ \\
\hline & $\begin{array}{l}\text { Why? } \\
\text { Challenge }\end{array}$ & $\begin{array}{l}\text { The child uses the } \\
\text { word „why” alone } \\
\text { or in a broader } \\
\text { statement to provoke } \\
\text { the other side to } \\
\text { statements of } \\
\text { justification. }\end{array}$ & $\begin{array}{l}\text { Why not? Can we go } \\
\text { there after all? }\end{array}$ \\
\hline \multirow[t]{5}{*}{ Unilateral } & Assertion & $\begin{array}{l}\text { Demand, firm } \\
\text { expression of his } \\
\text { own opinion, } \\
\text { position or wants. }\end{array}$ & $\begin{array}{l}\text { Let's go to the } \\
\text { amusement park! }\end{array}$ \\
\hline & $\begin{array}{l}\text { Simple } \\
\text { Request }\end{array}$ & $\begin{array}{l}\text { Asking with the use } \\
\text { of the polite form of } \\
\text { speech. }\end{array}$ & $\begin{array}{l}\text { Dad, can we go to the } \\
\text { amusement park? }\end{array}$ \\
\hline & $\begin{array}{l}\text { Simple } \\
\text { Statement }\end{array}$ & $\begin{array}{l}\text { A simple sentence } \\
\text { expressing desire, } \\
\text { preferences, without } \\
\text { justification; or the } \\
\text { situation in which } \\
\text { the child refers to an } \\
\text { opportunity to do } \\
\text { something without an } \\
\text { argument or method } \\
\text { as to how it could be } \\
\text { done. }\end{array}$ & $\begin{array}{l}\text { Mum, I like this train. } \\
\text { I want to have it. }\end{array}$ \\
\hline & $\begin{array}{l}\text { Mitigated } \\
\text { simple Request }\end{array}$ & $\begin{array}{l}\text { Mitigation of a } \\
\text { sentence by adding } \\
\text { the word „please”; } \\
\text { simple question with } \\
\text { the word „please” or } \\
\text { other polite form. }\end{array}$ & $\begin{array}{l}\text { Dear Mummy, please, } \\
\text { can we go to the } \\
\text { amusement park? }\end{array}$ \\
\hline & Plead & $\begin{array}{l}\text { Asking in the form } \\
\text { of supplication; } \\
\text { making request in } \\
\text { a begging manner; } \\
\text { asking with } \\
\text { "promising } \\
\text { somebody the } \\
\text { moon." }\end{array}$ & $\begin{array}{l}\text { Say: Mummy, please, } \\
\text { I really want to go, } \\
\text { and do this (child } \\
\text { gesture shows the } \\
\text { folded hands in } \\
\text { prayer). }\end{array}$ \\
\hline
\end{tabular}




\begin{tabular}{lll}
\hline Fait Accompli & $\begin{array}{l}\text { When something } \\
\text { has already }\end{array}$ & $\begin{array}{l}\text { Take a box, to sort } \\
\text { out the rails and start } \\
\text { happened or been } \\
\text { done and cannot be }\end{array}$ \\
changed; the child & $\begin{array}{l}\text { (colleagues) will also } \\
\text { start to play. }\end{array}$ \\
proposes that & \\
protagonist should & \\
& openly do what one \\
& wants and the other \\
& will change their \\
& minds.
\end{tabular}

\begin{tabular}{lll}
\hline Force & The child proposes & Sort out train and the \\
to use violence. & rails. If they will not \\
& want (to play) - hit \\
& them.
\end{tabular}

Indirect Bilateral Deceit

\section{Strategies}

\begin{tabular}{|c|c|c|}
\hline Deceit & $\begin{array}{l}\text { An attempt to } \\
\text { deceive someone by } \\
\text { lying or concealing } \\
\text { information; induce } \\
\text { somebody to do } \\
\text { something by } \\
\text { flattery, white lie } \\
\text { or similar. }\end{array}$ & $\begin{array}{l}\text { She can lie a little bit, } \\
\text { and say that other } \\
\text { children from her } \\
\text { school with parents } \\
\text { also go to the } \\
\text { amusement park. }\end{array}$ \\
\hline Hinting & $\begin{array}{l}\text { Communicates } \\
\text { wants, but not } \\
\text { directly; the child } \\
\text { suggests, implies, } \\
\text { mentions his/her } \\
\text { wants as an aside. }\end{array}$ & $\begin{array}{l}\text { He can say something } \\
\text { like: "You have a very } \\
\text { nice train. You know } \\
\text { friends share (their) } \\
\text { toys." }\end{array}$ \\
\hline $\begin{array}{l}\text { Thought } \\
\text { Manipulation }\end{array}$ & $\begin{array}{l}\text { The child } \\
\text { manipulates, } \\
\text { changes the } \\
\text { situation to its } \\
\text { advantage; for } \\
\text { example, child turns } \\
\text { the anger of the } \\
\text { persuaded person } \\
\text { around and directs } \\
\text { it toward the } \\
\text { persuaded person. }\end{array}$ & $\begin{array}{l}\text { He can tell his mother } \\
\text { that now he feels bad } \\
\text { but play can really } \\
\text { help with that. }\end{array}$ \\
\hline Guarantee & $\begin{array}{l}\text { Ensuring, giving } \\
\text { guarantees which } \\
\text { are beyond the } \\
\text { reach of the impact o }\end{array}$ & $\begin{array}{l}\text { „Dad, I'm sure I am } \\
\text { not missing a single } \\
\text { part!” }\end{array}$ \\
\hline
\end{tabular}


a person; in the simplest form denial of arguments of the parent.

\begin{tabular}{lll}
\hline Indirect & Question that & Convincing parents to \\
Question & indirectly refers & go to amusement park \\
& to the argument & child ask a question: \\
& suggests the desired & "Do you like \\
& direction of & roundabouts?" \\
thinking. &
\end{tabular}

\begin{tabular}{lll}
\hline $\begin{array}{l}\text { Appeal to } \\
\text { Higher }\end{array}$ & $\begin{array}{l}\text { The reference to a } \\
\text { person who is an }\end{array}$ & $\begin{array}{l}\text { "But Miss (school } \\
\text { teacher) said that are } \\
\text { only intelligent games } \\
\text { in the play centre!” }\end{array}$ \\
& $\begin{array}{l}\text { authority for both (parents, } \\
\text { teachers) or to a }\end{array}$ & \\
& standard - for \\
& example, moral or \\
& social principle, \\
& such as helping \\
& your neighbor.
\end{tabular}

Emotion An attempt to put Kiss dad, or give him
Agent the other side in the an ice cream. And desired mood-such when he smiles-talk as a good mood (e.g., to him nicely. kissing, hugging) or to provoke guilt.

\begin{tabular}{|c|c|}
\hline $\begin{array}{l}\text { Emotion } \\
\text { Target }\end{array}$ & 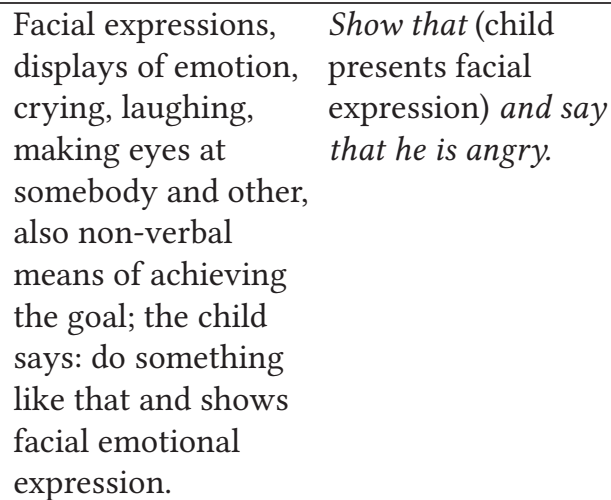 \\
\hline
\end{tabular}

\begin{tabular}{lll}
\hline Unilateral & $\begin{array}{l}\text { Indirect } \\
\text { Threat }\end{array}$ & $\begin{array}{l}\text { Implying that negati- Referring to a } \\
\text { ve consequences will colleague who does } \\
\text { occur if the persu- not want to play with } \\
\text { aded person does not a train: I will never } \\
\text { accept the plan. }\end{array}$
\end{tabular}




\begin{tabular}{|c|c|c|}
\hline Politeness & $\begin{array}{l}\text { Exceptionally good } \\
\text { child behavior } \\
\text { requiring significant } \\
\text { rewards important: } \\
\text { The child does not } \\
\text { explain the role of } \\
\text { such behaviour like } \\
\text { in a strategy to } \\
\text { manipulate or } \\
\text { influence the target } \\
\text { emotions. }\end{array}$ & $\begin{array}{l}\text { He/She must be very } \\
\text { nice for mum. }\end{array}$ \\
\hline $\begin{array}{l}\text { Politeness } \\
\text { and Personal } \\
\text { Favors }\end{array}$ & $\begin{array}{l}\text { The correct behavior } \\
\text { and rewards (gift or } \\
\text { favor) important: } \\
\text { The child does not } \\
\text { explain the role of } \\
\text { such behaviour. }\end{array}$ & $\begin{array}{l}\text { The child must be } \\
\text { well-behaved. (he/she) } \\
\text { can give mum flowers, } \\
\text { wash the dishes. }\end{array}$ \\
\hline $\begin{array}{l}\text { No } \\
\text { Persuasion }\end{array}$ & $\begin{array}{l}\text { Answers without } \\
\text { persuasive proposal } \\
\text { "I don't know" } \\
\text { answers and similar. }\end{array}$ & $\begin{array}{l}\text { I don't know; there is } \\
\text { nothing to do. }\end{array}$ \\
\hline $\begin{array}{l}\text { Reality } \\
\text { Change }\end{array}$ & $\begin{array}{l}\text { The child proposes } \\
\text { how to change } \\
\text { reality in } \\
\text { accordance with } \\
\text { the expectations } \\
\text { of the person being } \\
\text { persuaded, not } \\
\text { communication } \\
\text { and persuasion. }\end{array}$ & $\begin{array}{l}\text { When a parent } \\
\text { believes that the } \\
\text { toy is too big and } \\
\text { will not fit in the } \\
\text { room: } \\
\text { Pack the other toys } \\
\text { and take them away. } \\
\text { It can make room for } \\
\text { the train. }\end{array}$ \\
\hline
\end{tabular}

